\title{
Intelligent Traffic Management based on IoT
}

\author{
Sonali P. \\ Kshirsagar \\ Student at Sanjivani \\ College of Engineering, \\ Kopargaon,SPPU, \\ Pune(M.S.), India
}

\author{
Priyanka $\mathrm{H}$. \\ Mantala \\ Student at Sanjivani \\ College of Engineering, \\ Kopargaon,SPPU, \\ Pune(M.S.), India
}

\author{
Gayatri D. Parjane \\ Student at Sanjivani \\ College of Engineering, \\ Kopargaon,SPPU, \\ Pune(M.S.),India
}

\author{
Kalyani G. Teke \\ Student at Sanjivani \\ College of Engineering, \\ Kopargaon,SPPU, \\ Pune(M.S.),India
}

\begin{abstract}
Traffic Congestion is a big issue in many large cities of India and traffic lights are basically used to control the flow of vehicle. Failure of signals, increasing number of vehicles, poor law enforcement, and bad traffic management has result in traffic congestion. One of the major issues with Indian cities is that we cannot expand the existing infrastructure more, so we have only one option available is better management of the traffic. The effectiveness of traffic control system depends on its ability to react on real-time traffic conditions. However, conventional traffic control system is not able to do this. whatever the traffic density high or low the signals are timed and run according to that time only. This result in increased traffic congestion along the roads which again result in significant air pollution, an increased safety risk and negative impact on the economy and the overall quality of life. In this paper, we tend to planned development smart traffic management System based on the internet of Things (IoT).The traffic light management is proposed and developed to support decision making of traffic officers. The system can detect the congestion level of every road at the intersection based on the density of car with facilitate of RFID technology.
\end{abstract}

\section{General Terms}

Radio Frequency Identification (RFID), Internet of Things(IoT).

\section{Keywords}

Traffic Congestion, Traffic light Control.

\section{INTRODUCTION}

In day-to-day life, we have to face several issues one of which is traffic congestion becoming more serious day after day. The major reason leading to traffic congestion is the increased number of the vehicle. The traffic jam is caused once the number of vehicles exceeds the available road capacity. In a country like India, there is an annual loss of 60,000 crores due to congestion including fuel wastage. Manual control of traffic by traffic officers or using predefined timers has been proven not an effective solution, but they are still being used in many places. Without taking an account of real-time traffic data into concern, it can happen that a green light is granted to an vacant lane while a lot of cars are lined up at a red light on the other lanes because the same time interval of green lights are granted to every lane. The operation of standard traffic lights which are presently deployed in many junctions are based on predetermined timing scheme, which is fixed during the installation and remain until further resetting.

This paper proposed to implement the IoT, agent and RFID technologies to improve traffic conditions and relieves the traffic pressure. The system senses and collects the vehicle information. Through collected period traffic data, the system will recognize current traffic density, traffic flow conditions and can predict the future traffic flow. So the system will additionally monitor and control moving vehicles. Constructing, associate intelligent traffic management system based on IoT includes a range of benefits like improvement of traffic congestion detection, reduction in traffic congestion and management prices, highly reliable, traffic safety and independence of atmospheric conditions.

\section{RELATED WORK}

In [1] it is given that to avoid issues that typically arise with standard traffic control systems, particularly those associated with image processing and beam interruption techniques. This RFID technique works with a multi-vehicle, multilane, multiroad junction area. It gives an efficient time management scheme, during which a dynamic time schedule is figured out in real time for the passage of every traffic column. The realtime operation of the system emulates the decision of a traffic policeman on duty. The quantity of vehicles in every column and the routing properties, upon which the calculations and the judgment are primarily based.

In [2] it is given that the RFID has been utilized in order to spot vehicles and three vital parameters as well as the common speed of vehicles at any aspect of an access point, the average time for waiting and queue length. They have been used supported information from the neural network for creating the most effective call throughout the method of finding out the duration of the cycle and proportion of inexperienced time for every of the access point. Implementation of this system is feasible within the shortest time and it's more robust perform in any atmospherics conditions, time or place compared to the similar system.

In [3] it is given that RFID devices are used as the entrée to a new phase of development of the knowledge society called as the "Internet of Things". During this new phase, devices with reduced machine capacity will communicate over the internet, generating a huge amount of data that adds worth to standard of living and the current business models. It will be used a low-price, open source and internet-ready platform, to perform this control. It should interpret signals from sensors, control signals and communicate over the network employing a straightforward middleware.

In [4] it is given that watching the activities of a car in the modern city and urban has become imperative for managing the traffic related problem. Latest data concerning mobile vehicles, such as their identification (number of plate), position, and speed are very important for smart traffic management and business analytics. To that end, RFID tags are placed on vehicles and readers are placed on roads based traffic observation systems have gained a lot of attention due to their price effectiveness. Typically the RFID readers are a lot of costlier than the RFID tags. This work explores the actual drawback of locating suitable places in a road network for RFID readers that can capture the huge amount of traffic data.

In [5] it's given to provide both practically important traffic data collection and management information and can trace criminal or illegitimate vehicles like stolen cars or vehicles that avoid tickets, tolls or vehicle taxes. Supported RFID technology, the system collects and calculates average speed 
and average flow information on every road of a district area in a city. It then transfers the messages from all the engorged roads in a very district space to the server among the district center via a communication program. Through a flooding formula, each server in a district center exchanges and updates data with all neighbor servers in several district centers therefore all that the servers in various district centers will get the whole latest congestion message in a city. Therefore, a dynamic navigation system will notice the shortest path that avoids congested roads.

\section{SYSTEM ARCHITECTURE}

The planned system architecture is shown in Fig.1 from which we can completely define a proposed system.

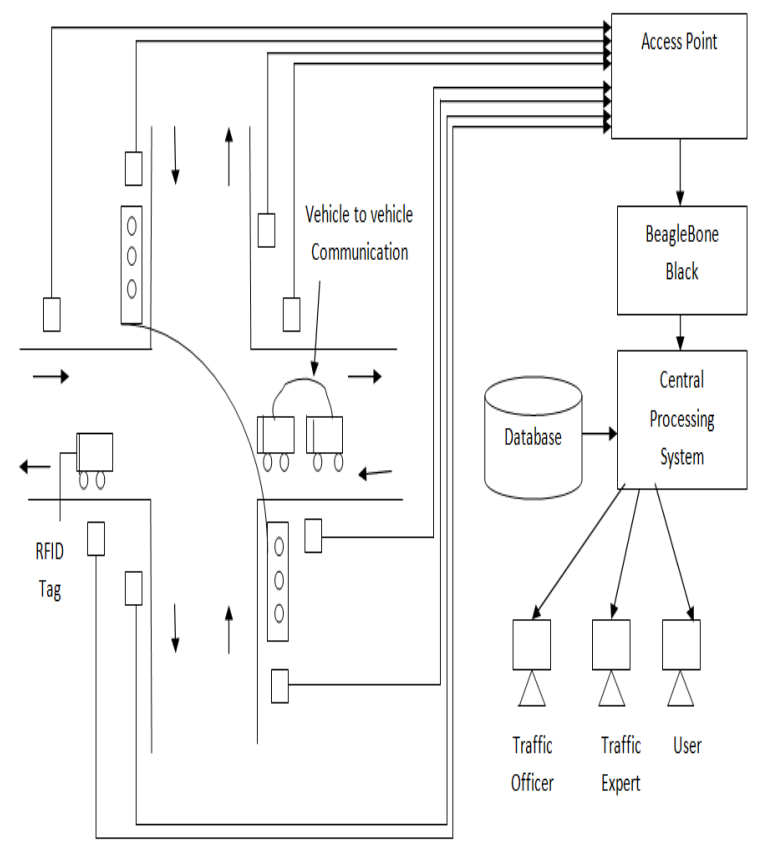

Fig1: Proposed System Architecture

\subsection{RFID Tag}

RFID tag is placed on each vehicle and tag is consisting of one unique number. Unique number is used for identifying vehicle.

\subsection{RFID Reader}

RFID reader is responsible for reading the RFID tag. All the information on the RFID tag is read by reader and transmits it to the Beagle Bone Black through the router.

\subsection{Routers}

Routers are the XBee devices which work independently. It accepts the various reading from RFID reader and forward the values to coordinator. Even though routers are optional part in the network because RFID reader can directly send the values to coordinator/gateway.

\subsection{Coordinator/Gateway}

Coordinator is XBee device which accept values from various routers and sensing nodes. Coordinator is connected to Beagle Bone Black which is connected to internet. All the accepted values will be sent to Beagle bone Black for processing by serial interface.

\subsection{BeagleBone Black / Raspberry pi}

We can perform all operations which we can perform by any computer device using BBB / Raspberry pi. BBB / Raspberry pi will communicate with gateway/coordinator by serial interface. The python API will regularly check for frame or values on serial port. As BBB / Raspberry pi is computer device we can connect internet to it via Ethernet port or Wi-Fi /wireless LAN. It will access the API from web server and dump all the reading into database.

\subsection{Access Point}

Access point is simple router which will provide internet connectivity to beaglebone black / raspberry pi board. Even if we are using local webserver we can provide connectivity via router to beaglebone black / raspberry pi.

\subsection{Web Server}

Web server will have a database and specific API from where the $\mathrm{BBB} /$ raspberry pi can connect and store values in database remotely. API and all will be developed by using MVC Framework in PHP and ome Python Scripts. Web server analyzes all the incoming values from the $\mathrm{BB}$ and analyze them, if any instant emergency vehicle then the higher priority is assigned to the vehicle and immediately decision is taken by system. If stolen vehicle is detected then system should set the signal to red for that lane and appropriate action is taken by the traffic officer.

\subsection{Computer web Application}

Web application can be accessed from any internet enabled device from which we can continuously monitor the traffic at the junction. Graphs, charts and history are used for effectiveness. Web application will be hosted on webserver. From web application we can remotely configure any XBee device such as switching ON OFF at any time. Web application will periodically analyze the values and perform actions depending on the conditions.

\subsection{Smartphone Application}

Smartphone app designed in Android will be connected to Internet i.e. specifically to web server. As web server will be connected to web server same this application will be working. From Smartphone we can monitor the environment continually without manual monitoring. Even all the remote devices are capable to configure remotely from application.

\section{MATHEMATICAL MODEL}

Set theory is the branch of mathematical logic that studies sets, which are collections of objects. Although any type of object can be collected into a set, set theory is applied most often to objects that are relevant to mathematics. A set is a collection of objects which are called the members or elements of that set. If we have a set we say that some objects belong (or do not belong) to this set, are (or are not) in the set. Also, we can say that sets consist of their elements.

According to set Theory the relevant mathematical model for this project is designed below.

Let, System as S set

$$
\mathrm{S}=\{\mathrm{I}, \mathrm{P}, \mathrm{R}, \mathrm{O}\}
$$

Where,

$\{\mathrm{I}\}$ is set of all given input set.

$\{\mathrm{P}\}$ is set of all processes in System.

$\{R\}$ is set of rules that drive your input set.

$\{\mathrm{O}\}$ is set of output expected from system.

Input

Set I represented as:

$\mathrm{I}=\{\mathrm{I} 1, \mathrm{I} 2\}$

Where, 
I1=User Information

$\mathrm{I} 2=$ Vehicle information

\section{Process}

Set $\mathrm{P}$ represents as:

$\mathrm{P}=\{\mathrm{P} 1, \mathrm{P} 2, \mathrm{P} 3, \mathrm{P} 4\}$

Where,

P1=Registration and Configure Device

P2= Calculate Density of Vehicles

P3= Analyze data

P4= View Statistics

\section{Rules}

Set $\mathrm{R}$ represents as:

$R=\{R 1, R 2, R 3\}$

Where,

R1=All device [sensing nodes] should be connected to coordinator.

R2=There should be no/less obstacle between sensing node and co-ordinator.

R3=Continuous internet connection/web-server should be connected to co-ordinator.

\section{Output}

Set $\mathrm{O}$ represents as:

$\mathrm{O}=\{\mathrm{O} 1, \mathrm{O} 2\}$

Where,

O1=Adjust the traffic light signal

$\mathrm{O} 2=$ Generate statistical information of traffic.

\section{Venn Diagram}

From Equations (2), (3), (4) and (5) we can draw the Venn diagram for the Inputs, Process, Rules, Output as shown in figure

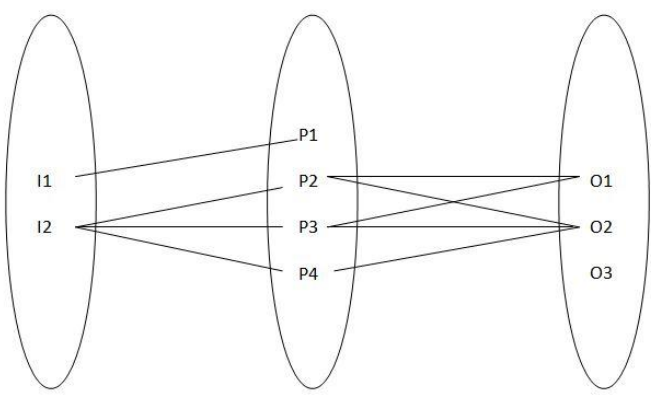

Fig 2: Venn Diagram

\section{Process state Diagram}

In a multitasking computer system, processes may occupy a variety of states. These distinct states may not actually be recognized as such by the operating system kernel. However, they are a useful abstraction for the understanding of processes. In a Fig 3 shows process state diagram, arrows indicating possible transitions between states.

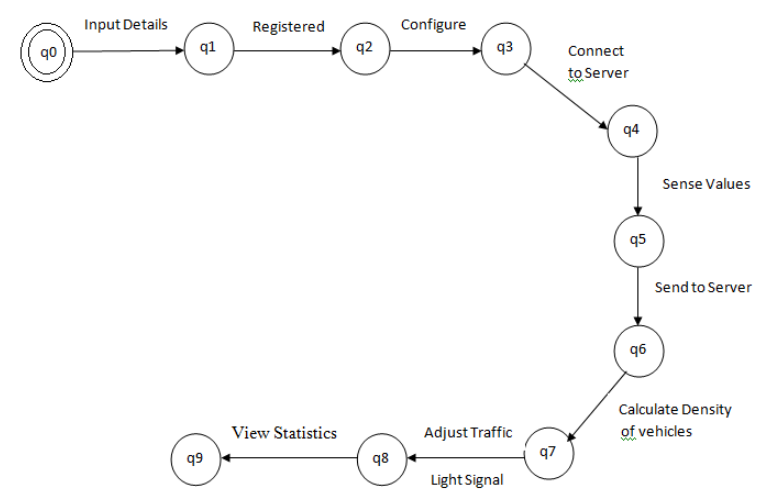

Fig 3: Process State Diagram

\section{CONCLUSION}

With Intelligent traffic management system based on the traffic density within the route, the manual work on the part of the traffic policeman is saved. As the complete system going to be automatic, it will need very less human interference. With stolen vehicle detection, the signal will automatically turn to red, so that the police officer will take applicable action if he/she is present at the junction. Also, SMS will be sent in order that they will plan to catch the stolen vehicle at the next possible junctions. Emergency vehicles like ambulance, fire trucks, have to be compelled to reach their destinations at the earliest. If they waste a lots of time in traffic jams, precious lives of many individual may be in danger. With emergency vehicle clearance, the traffic signal will turn to green as long as the emergency vehicle is waiting at the traffic junction. The signal turns to red, solely when the emergency vehicle passes through.

\section{REFERENCES}

[1] K.A. Al-Khateeb, J. A. Johari and W. F. Al-Khateeb, "Dynamic traffic light sequence algorithm using RFID", Journal of Computer Science, vol.4, no.7, 2008. Access Date: $21 / 07 / 2016$.

[2] S. Mohammadi, A. Rajabi, M.Tavassoli, "Controlling of traffic lights using RFID technology and neural network", Advanced Materials Research, vol.433, pp. 740-745, 2012. Access Date: 21/07/2016.

[3] R. M. Cardoso, N. Mastelari and M. F. Bassora, "Internet of things architecture in the context of intelligent transportation system case study towards a web-based application development", presented at $22^{\text {nd }}$ International congress of Mechanical Engineering (COBEM 2013). Access Date:21/07/2016.

[4] J. Paul et al., "RFID based vehicular networks for smart cities", presented at 2013 IEEE $29^{\text {th }}$ International Conference on Data Engineering Workshops (ICDEW), 2013. Access Date: $21 / 07 / 2016$.

[5] W. Wen, "An intelligent traffic management expert system with RFID technology", Expert System with Applications, vol. 37, no. 4, pp. 3024-3035, 2010. Access Date: 09/07/2016. 